\section{Tuberculosis and War}

IN a recent paper on this subject (Paris méd., 1, 52 ; 1940), Dr. E. Rist, of Paris, remarks that war favours the extension and aggravation of tuberculosis not only in belligerent nations but also in neutral countries, owing to the economic disturbance caused by the blockade, the scarcity of indispensable articles due to the destruction of merchant shipping and the hindrances of all kinds offered to the transport of goods by land and sea. During the War of 1914-18, the mortality curve from tuberculosis, which had fallen from 1900 to 1914 , rose sharply from 1915 to 1918, and did not decline again until after the conclusion of peace. Among the numerous causes of an increase of endemic tuberculosis in war-time, one of the most serious is the rapid and wholesale evacuation of urban and rural populations to districts which are not sufficiently prepared to receive them, with the result that numerous healthy persons become infected with tuberculosis by those suffering from an active form of the disease.

Another factor leading to increase is the interruption of the most successful method of treatment of pulmonary tuberculosis, consisting in various forms of collapse therapy, especially artificial pneumothorax, caused by evacuation of patients to areas where there are no practitioners familiar with the technique. Other factors found to be responsible for the spread of tuberculosis are overwork, especially among those engaged in war industries of various kinds, under-feeding, as was illustrated in Denmark during 1914-18, and mental worry, the importance of which was emphasized by Laennec long ago. In conclusion, Dr. Rist, while admitting the necessity of an ample supply of tuberculosis experts in the armed forces, emphasizes the importance of restoring to civil practice a large number of them who are employed on quite unsuitable duties.

\section{British Museum (Natural History)}

Lecture tours in the British Museum (Natural History) on Saturdays at 3 p.m., and on the first Sunday in each month at 3 p.m. have been arranged. London museums are re-opening their doors, and although many treasures have had to be moved away to safety from the Natural History Muweum, their places have been filled to some extent by special exhibitions and new grouping. Two of the galleries are being used for a special exhibition to show Nature in the service of man. The exhibits illustrate the animals and plants from which our most important textiles are produced; sources of oil, animal, vegetable, and mineral, and some of the industries in which the various oils are needed; materials from which cosmetics and surgical requisites are prepared; the use made of spiders' webs and the origin of domestic breeds of poultry, cattle, pigs, etc. There is a section showing the animals particularly useful in war, such as white mice, canaries, reindeer, and Airedale dogs. Another gallery which has been proving a great attraction during the few weeks of limited opening is the Whale Hall, where a full-size model of a Blue Whale
92 feet long is on view-a treasure certainly, but much too large for evacuation !

\section{Night-Shining Eyes}

Most people are familiar with the greenish gleam which shines from the eyes of a cat when a beam of light is directed upon them at night, and are aware that the glow can be seen only when the observer's line of vision is closely parallel with the beam of light. The phenomenon has been investigated in many animals by E. P. Walker, assistant director of the National Zoological Park of the Smithsonian Institution, and his results are referred to in the current Year Book of the Institution. The apparatus used in the tests was a reflecting head lamp, similar to a hand torch, worn on the forehead and connected with a three-cell battery in his pocket. The best results were obtained with a beam of moderate intensity, the effect of an intense beam being to make the glow less conspicuous or entirely to prevent its appearance. The shining is due to reflection from some surface in the eye, but its colour and character vary with the kind of animal. Colour ranges ran from silvery to blue-green, pale gold, reddish-gold, brown, amber and pink, and while most resembled reflection from a burnished metal surface, those of crocodiles and alligators gave the observer the impression of gazing into "a brilliantly glowing pinkish opening in a dull-surfaced bed of coal".

In the case of glowing eyes, the appearance is as if one looked through the pupil of the eye and saw reflection from the surface of the retina, but where the gleam was metallic in character there was no impression of looking into the interior of the eye. In the latter case, however, a difficulty arose because in most cases the reflection disappeared at a distance closer than from eight to twenty feet, so that the actual reflecting surface could not be determined. In some forty species of mammals and reptiles tests were made with red and blue coloured beams of light, but these made little change in the reflected gleam except to add a corresponding tinge of red or blue, a result which confirms the suggestion of simple reflection without any real animal light. To some degree there is a family resemblance in the character of the gleams, for most rodent eyes shine dully in brown, hazel or amber, although in porcupines the reflection is brilliantly silver. No shine was obtained from the eyes of higher apes or monkeys and no proof of the alleged shining of human eyes, yet, curiously enough, the most brilliant reflections of all were from the eyes of two of the lemurs, the slow loris and the potto.

\section{Ethnological Reconnaissance in New Guinea}

Mucr of the Mandated Territory of New Guinea is still uncontrolled, and even unexplored. Notwithstanding the difficulties of the country, the policy of exploration with a view to control is pursued with as little intermission as circumstances allow and has made substantial additions to knowledge in the information collected relating to the culture of previously unvisited or unknown peoples of the interior, notably in the regions adjacent to Mt. 